\title{
Early intervention in psychotic disorders: faith before facts?
}

\author{
P. Bosanac' ${ }^{1}$ G. C. Patton ${ }^{2}$ and D. J. Castle ${ }^{3 *}$ \\ ${ }^{1}$ The University of Melbourne, Melbourne, Australia \\ ${ }^{2}$ Centre for Adolescent Health, Royal Children's Hospital; Murdoch Childrens Research Institute; and Department of Paediatrics, \\ The University of Melbourne, Melbourne, Australia \\ ${ }^{3}$ St Vincent's Health and The University of Melbourne, Melbourne, Australia
}

\begin{abstract}
This paper reviews the literature on early intervention in psychotic disorders, weighs the cons of this approach, and makes suggestions for clinicians and researchers regarding how to interpret and respond to what is still an embryonic evidence-base, notably in terms of any long-term benefits.
\end{abstract}

Received 23 April 2009; Revised 30 April 2009; Accepted 19 May 2009; First published online 2 July 2009

Key words: Antipsychotics, early intervention, high risk, schizophrenia.

\section{Introduction}

One of the most striking developments in psychiatric services in the past decade has been the establishment of early intervention programmes for psychotic disorders around the world (McGorry et al. 2007; McGorry, 2009). The attractiveness of these models of care is clear. For a group of disorders where there has been a pessimistic view of outcome, early intervention strategies offer patients, families and clinicians a more optimistic view of the future. One major aim in early intervention is to reduce the duration of untreated illness (DUP) by engaging affected individuals and their carers in flexible models of non-stigmatizing and minimally traumatic care, which in turn enhance recovery. The focus on recovery and relapse prevention involves intense individual, group and family psychological interventions appropriate to the individual, along with addressing psychiatric and substance abuse co-morbidities (Yung et al. 1999) and the judicious use of psychotropic medication (Drake \& Lewis, 2008). Yet there is still limited research into the effectiveness of such programmes, particularly around longer-term outcomes (Craig, 2003), and overall the concept continues to fuel academic debate (e.g. McGorry, 2009; Pelosi, 2009). Indeed, criticism has also emerged around the potential for 'overmedicalizing' problems. For health services policy, the development of early psychosis strategies raises important questions about where best to invest limited

* Address for correspondence: Professor D. J. Castle, Chair of Psychiatry, St Vincent's Health and The University of Melbourne, Level 2, 46 Nicholson Street, Fitzroy, Victoria 3065, Australia. (Email: david.castle@svhm.org.au) funds for psychiatric services and how to integrate early psychosis initiatives into broader services.

\section{'Caseness' in early psychosis}

Current targets for early psychosis are broad. They encompass the at-risk mental state (ARMS), which may extend to 5 years prior to the onset of frank psychosis; the first episode that satisfies threshold criteria for syndromal classification; and the ensuing early and late recovery phases in the first year after acute treatment (McGorry et al. 2007). There are, however, considerable challenges in defining a 'case' for intervention. Even in those with clear-cut psychosis, definitive diagnosis is difficult. Schizophrenia is followed by bipolar and major depressive disorder with psychotic features in having the highest prospective diagnostic consistency over a 2-year period (Subramaniam et al. 2007). Criteria B and C of DSMIV-TR (APA, 2000) preclude the diagnosis of schizophrenia close to onset and potentially skew early intervention to other psychotic disorders that are by their nature more transient and more amenable to intervention (McGlashan, 2007). This is perhaps linked to a trend in the early psychosis literature to 'Kraepelin bashing', taking the father of dementia praecox to task for being overly negative about the outcomes of the disorder. Yet Kraepelin's delineation of dementia praecox was of an early onset, male predominant, severe illness with a poor longitudinal trajectory (Murray et al. 1992); this is only one subgroup in what ICD-10 and DSM-IV-TR call 'schizophrenia'. Equating the two diagnostic constructs is misleading. 
A 'transdiagnostic' approach to first-episode psychosis, with its inherent limitations in validity and reliability, affects the generalizability of outcome studies as the natural history of different disorders varies (Ketter et al. 2003). For this reason phenomenological approaches to early schizophrenia that encompass altered subjective experiences, rather than relying entirely on syndromal diagnosis (as inherent in DSM-IV-TR and ICD-10), are emerging as attractive areas for further study (Parnas, 2005). However, this approach is limited by the high prevalence and low predictive power of psychotic experiences in the general population. Only a minority of these individuals can be considered to have a treatable 'disorder' (Konings et al. 2006).

\section{The DUP conundrum}

A recent consensus statement for gauging the effectiveness of early intervention programmes included the following objectives: reduction in DUP to $<3$ months; suicide rates $<1 \%$ within the first 2 years from diagnosis; employment and education rates matched to non-affected peers at 5 years; reported satisfaction in these domains; and social attainment occurring in $\leqslant 90 \%$ of affected people (Bertolote \& McGorry, 2005). To what extent is such a desire supported by the available literature?

Reduction in DUP has been widely adopted as a surrogate for better clinical outcomes. Yet there are many difficulties in this approach. The accurate measurement of DUP in a disorder that often has its origins in early neurodevelopmental aberration and that carries disability, for some individuals, from very early in life is arbitrary (Jones et al. 1994). As Häfner et al. (1992) have shown, the prodrome of schizophrenia is commonly non-specific, with prominent mood and negative rather than positive psychotic symptoms. Attempts at refining the 'ultra-high-risk' mental state has not helped clinicians much in that most of those who transition to psychosis do so fairly early after detection. The transition rate is strongly dependent upon the base rate of psychosis in the sample population, making the predictive value very poor in general population or routine clinical samples (Yung et al. 2006). Even in highly enriched samples the positive predictive value seems to be low, with around $10 \%$ making a transition within 6 months of first assessment (Yung et al. 2006). Furthermore, the greater the need to define smaller ultra-high-risk groups to achieve sufficient predictive power within the clinic, the smaller the effect is likely to be on preventing transition to psychosis, as the majority of those potentially at risk will not be identified for clinic attendance (see Rose, 1992).
There are also challenges in the identification of young people most at risk of the adverse outcomes of psychotic illness. It is clear that early detection strategies can recruit people with lower levels of symptomatology and less deteriorating social function than mainstream mental health services. Yet there is little evidence that they recruit a high proportion of patients with the worst prognosis, that is those with a prodrome of $>2$ years (Friis et al. 2005). Thus, it is possible that early detection is likely to identify individuals with an inherent tendency to better outcomes. For those who do progress to psychosis there are further difficulties. Given the high rate of non-transition, many will be exposed to antipsychotic medications, which carry their own risks and side-effects, in addition to the potential stigmatizing effects of being identified as 'at risk'.

The extent to which DUP independently predicts outcomes remains a problem, as the onset for the most severe illnesses may be insidious, with flattened affectual responses and impaired social functioning being the early features (Morgan et al. 2006). Whether early intervention programmes have a greater impact on DUP in this group of patients than usual mental health services is questionable.

Finally, despite reports of associations between DUP and clinical and functional outcomes (Norman et al. 2005; Perkins et al. 2005), the impact of reduced DUP on longer-term outcomes is equivocal, and the mechanism whereby such an effect might be mediated is open to conjecture (Marshall et al. 2005). One suggested mechanism is that clinical interventions are 'neuroprotective'. This term has been applied to interventions that may reduce the loss of, or promulgate, glial or neuronal progenitor cells that otherwise would have been affected during the transition to psychotic illness such as schizophrenia (Berger et al. 2003). Early and late neurodevelopmental processes, with the latter occurring during the transition to illness, have been implicated in schizophrenia. The evidence for late neurodevelopmental changes comes from progressive magnetic resonance imaging (MRI) changes, particularly in the prefrontal and medial temporal regions, of people at ultra-high risk of developing schizophrenia, and increased prefrontal grey matter loss in first-episode psychosis patients compared with normal controls (Pantelis et al. 2007). However, other studies have not found an association between DUP and brain volume, including in the hippocampi (Ho et al. 2005). At this juncture, the aetiology of late neurodevelopmental changes is speculative (Pantelis et al. 2007), as is the scope for interventions that ameliorate such changes with associated clinical benefit. 


\section{Longer-term outcomes}

Developmentally appropriate and accessible models of care (McGorry, 2002) and the development of clinical staging (McGorry, 2007) have been proposed as important elements of optimal care in early psychosis, but the evaluation of these interventions in randomized controlled trials is difficult. The challenges include defining an appropriate 'control' condition; statistical power; and operationalizing experimental and control interventions. The OPUS trial in Denmark and the Lambeth Early Onset (LEO) study in London (Craig et al. 2004) both compared specialist early psychosis interventions with 'usual care'. The OPUS study recruited people aged 18 to 45 years with ICD-10 (WHO, 1993) schizophrenia or related disorders who had not been on continuous antipsychotic medication for more than 12 weeks. In that study, there were short-term benefits for the intervention group in terms of independent living and homelessness; improved psychotic symptoms ; lower levels of substance abuse; and better global functioning at 2 years follow-up. However, as Patton et al. (2007) point out, outcome measurements were not blinded and there was high attrition that might well have biased outcomes. Furthermore, and more importantly to the current discourse, benefits on positive and negative symptoms of schizophrenia, global functioning, secondary substance use and antipsychotic were not sustained at the 5-year follow-up (Bertelsen et al. 2008). Participants in the LEO study were aged 16-40 years, and had presented to mental health services for the first or second time (the latter having disengaged without treatment after presenting once) with ICD-10 non-affective psychoses and the absence of organic psychosis or primarily substance addiction. Beneficial 12- and 18-month outcomes were found for the specialist intervention in global functioning, hospitalization rates, and vocational and social parameters (Garety et al. 2006). However, controlling for differences in baseline parameters such as previous psychotic episodes and ethnicity obviated the advantage in terms of relapse rates (Patton et al. 2007). At 5 years follow-up any benefit in terms of reduced hospital use had disappeared (Gafoor et al. 2008). In an earlier 9-month comparison of an assertive outreach model of care and treatment as usual for people who had first service contact for a psychotic disorder within the preceding 5 years, Kuipers et al. (2004) found there were no significant differences on measures of psychopathology, quality of life and overall functioning. Thus, it seems that short-term benefits of early psychosis interventions are not consistently translating into longer-term gains.

A further challenge lies in determining which elements of early intervention programmes have any effect. Most studies have used multifaceted interventions with little possibility of disaggregating the elements. It seems that cognitively orientated psychological interventions have a significant role in the management of early psychotic disorders, but further empirical study of their type and utility in terms of illness phase and cost-effectiveness is necessary (Haddock \& Lewis, 2005). Similarly, family interventions, including combination with cognitive behavioural therapy, require further evaluation of their effectiveness in this population (Lewis et al. 2005), as do comprehensive and group interventions (Penn et al. 2005). There is preliminary evidence that vocational interventions, centred on individual placement and support, may confer better employment outcome at 6 months than treatment as usual, in early psychotic disorders (Killackey et al. 2008), but the impact on longer-term vocational functioning is not known, and in any event, such interventions may be effective in the short term at any stage of illness (McGurk et al. 2007).

A reduction in suicide rates is a worthy aim of early psychosis services, yet again the evidence that they are effective in this regard, expressly over longer time intervals, is limited. Suicidal plans and attempts in early psychosis are linked with suicidal ideation, psychotic and depressive symptomatology and are thus potentially amenable to early clinical intervention (Melle et al. 2006; Bertelsen et al. 2007). A retrospective, population-based study of people who had contact with specialized mental health services for early psychotic disorders found that the suicide rate was half that of those with similar disorders without specialized intervention over the initial 3 years, but the risk was not diminished beyond this and up to a period of 8.5 years (Harris et al. 2008). In addition, observational studies of this type suffer from the problem of 'zero time shift', such that the simple fact that the intervention is at an earlier stage of illness makes outcomes appear more favourable (Sackett et al. 1991).

\section{The problem of labelling, and potential treatment-related harm}

Another set of issues is the ethical considerations of early intervention such as stigma and avoiding iatrogenic harms, particularly in intervention during a pre-psychotic phase (McGlashan, 2005). In a study of comparative attitudes about early intervention in psychotic disorders, young people and their parents were found to be more likely than clinicians to favour informal social support, generic counselling and stress reduction over seeking help from psychiatrists, mental health services and antipsychotic medication (Jorm et al. 2008). Although these findings may not seem surprising, they may represent both an impediment to 
accessing help and treatment adherence and an opportunity for improving mental health literacy. However, the labelling of young people as 'mentally ill', an inevitable consequence of engagement with clinical services, is potentially damaging in terms of personal and family stigma, and pathologizes what might be normal developmental processes.

Despite reported clinical benefits in controlled studies of antipsychotic medications in the ARMS, including olanzapine versus placebo for symptoms over 8 weeks (Woods et al. 2003), and risperidone and cognitive therapy versus supportive case management for progression to psychosis over 6 months (McGorry et al. 2002), the unequivocal clinical benefit of antipsychotic medication in the ARMS has not been demonstrated (Remington, 2005). In addition, the superior clinical response of antipsychotics in early psychotic disorders (Perkins et al. 2005) compared with later illness is counterbalanced by the limitations of diagnostic specificity and sensitivity of this temporal phase, greater sensitivity to side-effects, and ongoing increased risk of relapse potentially heightened by cessation of medication (Remington, 2005). There is also the spectre of adverse sequelae of treatment with some antipsychotic medications, including psychotropicrelated metabolic disturbance (including weight gain, hyperlipidaemia and diabetes), leading to potential early death (Buckley et al. 2008). Most recently, findings of an excess of sudden cardiac death associated with antipsychotics has led to caution being advocated about the over-liberal use of such drugs (Schneeweiss \& Avorn, 2009).

\section{Service delivery implications}

Health service planners worldwide have accepted early intervention frameworks as core features of the psychiatric service system, even though there is no evidence for improvement in longer-term outcomes (discussed above). There is also the risk of diverting funding away from those with the most severe forms of illness who are still likely to require concerted ongoing comprehensive care well beyond the early years of illness (Harrison et al. 2001). In addition, there is a difficulty that commitment to rolling out early intervention services on a large scale may make the conduct of further large-scale, longer-term studies infeasible in many countries in the future.

Specialized treatment plans for early psychosis patients are arguably no different to those that would be considered best practice by multidisciplinary psychiatry teams, and should be provided to all patients. Yet the creation of specialized early psychosis intervention programmes may disrupt the continuity of care by transfer back to referring mental health or primary care clinicians after a crucial or designated period of intervention (Pelosi, 2009). The latter referral back to other mental health agencies following intensive, but finite, intervention in early schizophrenia is unlikely to be sufficient to maintain any early clinical and functional improvements (Linszen et al. 1998).

\section{Conclusions}

In this review, we ask whether the early psychosis movement, however well-intentioned, has overreached itself, setting dogma before evidence. Although it is likely that there are early clinical outcome benefits from early intervention for some individuals with psychotic disorders, the evidence that such benefits are sustained and meaningful in the longer term is equivocal. There is a lack of evidence that early interventions do much for those who have illnesses that are, from the outset, likely to have a poor longitudinal trajectory. Given both the low rates of transition to psychosis and the small proportion of psychosis cases that pass through ARMS clinics, it is difficult to justify this strategy outside of a research setting.

Clinicians and researchers might be better to concentrate their attention on advocating for the provision of better, fully integrated services for all people with psychotic disorders, irrespective of the stage of their illness. Such an approach would prevent the evolution of further silos within mental health services; avoid patients having to negotiate additional barriers such as transitioning from early psychosis to 'general adult' services; and prevent further erosion of the expertise of 'generic' services as skilled and well-intentioned clinicians succumb to the allure of boutique early psychosis services.

\section{Declaration of Interest}

None.

\section{References}

APA (2000). Diagnostic and Statistical Manual of Mental Disorders, 4 th edn, text revision (DSM-IV-TR). American Psychiatric Association: Washington, DC.

Berger GE, Wood S, McGorry PD (2003). Incipient neurovulnerability and neuroprotection in early psychosis. Psychopharmacology Bulletin 37, 79-101.

Bertelsen M, Jeppesen L, Petersen L, Thorup A, Ohlenschlaeger P, Quach PL, Christensen TO, Krarup G, Jorgensen J, Nordentoft M (2007). Suicidal behaviour and mortality in first-episode psychosis: the OPUS trial. British Journal of Psychiatry 191 (Suppl. 51), s140-s146.

Bertelsen MT, Jeppesen L, Petersen A, Thorup A, Ohlenschlaeger P, Quach PL, Christensen TO, Krarup G, Jorgensen J, Nordentoft M (2008). Five-year follow-up of a 
randomized multicenter trial of intensive early intervention vs standard treatment for patients with a first episode of psychotic illness. Archives of General Psychiatry 65, 762-771.

Bertolote J, McGorry P (2005). Early intervention and recovery for young people with early psychosis: consensus statement. British Journal of Psychiatry 187, s116-s119.

Buckley PF, Foster A, Miller B (2008). Schizophrenia host vulnerability and risk of metabolic disturbances during treatment with antipsychotics. Focus 6, 172-179.

Craig T (2003). A step too soon or a step too far? Early intervention in psychosis. Journal of Mental Health 12, 335-339.

Craig TJ, Garety P, Power P, Rahaman N, Colbert S, Fornells-Ambrojo M, Dunn G (2004). The Lambeth Early Onset (LEO) Team: randomised controlled trial of the effectiveness of specialised care for early psychosis. British Medical Journal 329, 1067.

Drake R, Lewis S (2008). A treatment approach to the patient with first episode schizophrenia. In Pharmacological and Psychosocial Treatments in Schizophrenia, 2nd edn (ed.

D. J. Castle, D. L. Coplov, T. Wykes and K. T. Mueser), pp. 205-219. Informa Healthcare: London.

Friis S, Vaglum P, Haahr U, Johannessen JO, Larsen TK, Melle I, Opjordsmoen S, Rund BR, Simonsen E, McGlashan T (2005). Effect of an early detection programme on duration of untreated psychosis. British Journal of Psychiatry 187, s29-s32.

Gafoor R, Craig T, Garety P, Power P, McGuire P (2008). Do the benefits of early intervention (EI) treatments persist? 5-year follow-up. Schizophrenia Research 98, 83-88.

Garety PA, Craig TK, Dunn G, Fornells-Ambrojo M, Colbert S, Rahaman N, Read J, Power P (2006). Specialised care for early psychosis: symptoms, social functioning and patient satisfaction: randomised controlled trial. British Journal of Psychiatry 188, 37-45.

Haddock G, Lewis S (2005). Psychological interventions in early psychosis. Schizophrenia Bulletin 31, 697-704.

Häfner H, Riecher-Rossler A, Hambrecht M, Maurer K, Meissner S, Schmidtke A, Fatkenheuer B, Loffler W, van der Heiden W (1992). IRAOS: an instrument for the retrospective assessment of the onset of schizophrenia. Schizophrenia Research 6, 209-223.

Harris MG, Burgess PM, Chant DC, Pirkis JE, McGorry PD (2008). Impact of a specialized early psychosis treatment programme on suicide. Retrospective cohort study. Early Intervention in Psychiatry 2, 11-21.

Harrison G, Hopper K, Craig T, Laska E, Siegel C, Wanderling J, Dube KC, Ganev K, Giel R, van der Heiden W, Holmberg SK, Janca A, Lee PWH, Leon A, Malhotra S, Marsella AJ, Nakane Y, Sartorius N, Shen Y, Skoda C, Thara R, Tsirkin SJ, Varma VK, Walsh D, Wiersma D (2001). Recovery from psychotic illness : a 15- and 25-year international follow-up study. British Journal of Psychiatry 178, 506-517.

Ho B-C, Alicata D, Carmencita M, Andreasen NC (2005). Hippocampus volume and treatment delays in first-episode schizophrenia. American Journal of Psychiatry $162,1527-1529$.
Jones P, Rodgers B, Murray R, Marmot M (1994). Child developmental risk factors for adult schizophrenia in the British 1946 birth cohort. Lancet 344, 1398-1402.

Jorm AF, Morgan AJ, Wright A (2008). A comparison of clinician, youth, and parent beliefs about helpfulness of interventions for early psychosis. Psychiatric Services 59, 1115-1120.

Ketter TA, Wang PW, Becker OV, Nowakowska C, Yang Y (2003). Psychotic bipolar disorders: dimensionally similar to or categorically different from schizophrenia? Journal of Psychiatric Research 38, 47-61.

Killackey E, Jackson HJ, McGorry PD (2008). Vocational intervention in first-episode psychosis: individual placement and support v. treatment as usual. British Journal of Psychiatry 193, 114-120.

Konings M, Bak M, Hanssen M, van Os J, Krabbendam L (2006). Validity and reliability of the CAPE: a self-report instrument for the measurement of psychotic experiences in the general population. Acta Psychiatrica Scandinavica 114, 55-61.

Kuipers E, Holloway F, Rabe-Hesketh S, Tennakoon L (2004). An RCT of early intervention in psychosis: Croydon Outreach and Assertive Support Team (COAST). Social Psychiatry and Psychiatric Epidemiology 39, 358-363.

Lewis S, Tarrier N, Drake RJ (2005). Integrating non-drug treatments in early schizophrenia. British Journal of Psychiatry 187, s65-s71.

Linszen D, Lenior M, De Haan L, Dingemans P, Gersons P (1998). Early intervention, untreated psychosis and the course of early schizophrenia. British Journal of Psychiatry 172 (Suppl. 33), s84-s89.

Marshall M, Lewis S, Lockwood A, Drake R, Jones P, Croudace T (2005). Association between duration of untreated psychosis and outcome in cohorts of firstepisode patients. Archives of General Psychiatry 62, 975-983.

McGlashan TH (2005). Early detection and intervention in psychosis: an ethical paradigm shift. British Journal of Psychiatry 187, s113-s115.

McGlashan TH (2007). The DSM-IV version of schizophrenia may be harmful to patients' health. Early Intervention in Psychiatry 1, 289-293.

McGorry P (2002). The recognition and optimal management of early psychosis: an evidence-based reform. World Psychiatry 1, 76-83.

McGorry P (2007). Issues for DSM-V: clinical staging: a heuristic pathway to valid nosology and safer, more effective treatment in psychiatry. American Journal of Psychiatry 164, 859-860.

McGorry P (2009). Is early intervention in the major psychiatric disorders justified? Yes. British Medical Journal 337, a695.

McGorry P, Killackey E, Yung AR (2007). Early intervention in psychotic disorders: detection and treatment of the first episode and the critical early stages. Medical Journal of Australia 187, s8-s10.

McGorry PD, Phillips LJ, Yung AR, Francey S, Germano D, Bravin J, MacDonald A, Hearn N, Amminger P, O'Dwyer L (2002). A randomised controlled trial of interventions in the pre-psychotic phase of psychotic disorders. Archives of General Psychiatry 59, 921-928. 
McGurk SR, Twamley EW, Sitzer DI, McHugo GJ, Mueser KT (2007). A meta-analysis of cognitive remediation in schizophrenia. American Journal of Psychiatry 164, 1791-1802.

Melle I, Johannesen JO, Friis S, Haahr U, Joa I, Larsen TK, Opjordsmoen S, Rund BR, Simonsen E, Vaglum R, McGlashan T (2006). Early detection of the first episode of schizophrenia and suicidal behaviour. American Journal of Psychiatry 163, 800-804.

Morgan C, Abdul-Al R, Lappin JM, Jones P, Fearon P, Leese M, Croudace T, Morgan K, Dazzan P, Craig T, Leff J, Murray R (2006). Clinical and social determinants of duration of untreated psychosis in the ÆSOP first episode psychosis study. British Journal of Psychiatry 189, 446-452.

Murray RM, O'Callaghan E, Castle DJ, Lewis SW (1992). A neurodevelopmental approach to the classification of schizophrenia. Schizophrenia Bulletin 3, 319-332.

Norman RM, Lewis SW, Marshall M (2005). Duration of untreated psychosis and its relationship to clinical outcome. British Journal of Psychiatry. Supplement 187, s19-s23.

Pantelis C, Velakoulis D, Wood SJ, Yucel M, Yung AR, Phillips LJ, Sun DQ, McGorry PD (2007). Neuroimaging and emerging psychotic disorders: the Melbourne ultra-high risk studies. International Review of Psychiatry 19, 71-381.

Parnas J (2005). Clinical detection of schizophrenia-prone individuals. British Journal of Psychiatry 187, s111-s112.

Patton G, Hetrick SE, McGorry P (2007). Service responses for youth onset mental disorders. Current Opinion in Psychiatry 20, 319-324.

Pelosi A (2009). Is early intervention in the major psychiatric disorders justified? No. British Medical Journal 337, a710.

Penn DL, Waldheter EJ, Perkins DO, Mueser KT, Lieberman JA (2005). Psychosocial treatment for first-episode psychosis: a research update. American Journal of Psychiatry 162, 2220-2232.

Perkins DO, Gu H, Boteva K, Lieberman JA (2005). Relationship between duration of untreated psychosis and outcome in first-episode schizophrenia : a critical review and meta-analysis. American Journal of Psychiatry 162, 1785-1804.

Remington G (2005). Rational pharmacotherapy in early psychosis. British Journal of Psychiatry 187, s77-s84.

Rose G (1992). The Strategy of Preventive Medicine. Oxford University Press: Oxford.

Sackett DL, Haynes RB, Guyatt GH, Tugwell P (1991). Clinical Epidemiology: A Basic Science for Clinical Medicine. Little Brown \& Company: London.

Schneeweiss S, Avorn J (2009). Antipsychotic agents and sudden cardiac death: how should we manage the risk? New England Journal of Medicine 360, 294-296.

Subramaniam M, Pek E, Verma S, Chan YH, Chong SA (2007). Diagnostic stability 2 years after treatment initiation in the Early Psychosis Intervention Programme in Singapore. Australian and New Zealand Journal of Psychiatry 41, 495-500.

WHO (1993). The Tenth Revision of the International Classification of Diseases and Related Health Problems (ICD-10): Diagnostic Criteria for Research. World Health Organization: Geneva.

Woods S, Brier A, Zipursky R, Perkins DO, Addington J, Miller TJ, Hawkins KA, Marquez E, Lindborg SR, Tohen M, McGlashan TH (2003). Randomized trial of olanzapine versus placebo in the symptomatic treatment of the schizophrenic prodrome. Biological Psychiatry 54, 453-464.

Yung AR, Phillips LJ, Drew LT (1999). Promoting access to care in early psychosis. In The Recognition and Management of Early Psychosis (ed. P. McGorry and H. Jackson), pp. 80-84. Cambridge University Press: Cambridge.

Yung AR, Stanford C, Cosgrave E, Killackey E, Phillips L, Nelson B, McGorry PD (2006). Testing the ultra high risk (prodromal) criteria for the prediction of psychosis in a clinical sample of young people. Schizophrenia Research 84, 57-66. 